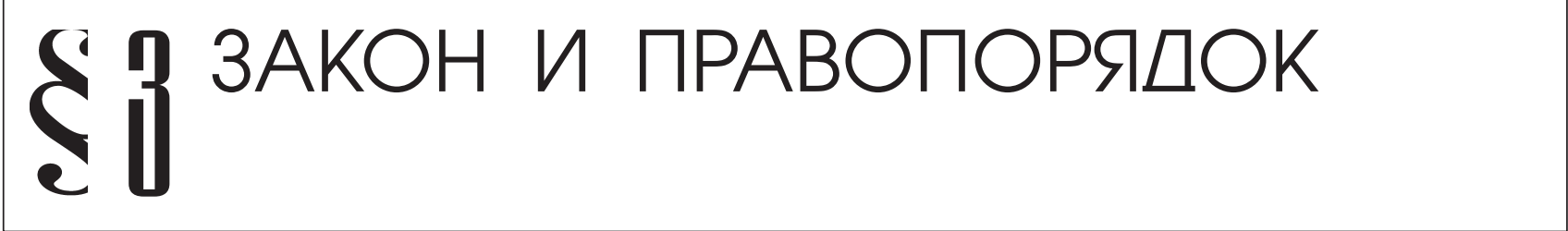

Кухарук В.В.

\section{ПРОБЛЕМЫ УГОЛОВНО-ПРАВОВОЙ ОХРАНЫ ЗДОРОВЬЯ НАСЕЛЕНИЯ: АНАЛИЗ, СОСТОЯНИЕ, ПУТИ ПРЕОДОЛЕНИЯ}

\begin{abstract}
Аннотация: Работа посвящена исследованию проблем уголовно-правового обеспечения оборота веществ в контексте международно-правовых (конвенционных) обязательств государства и законотворческих традиций в сфере безопасности здоровья населения. Оборот веществ представлен как элемент факторного комплекса, действие которого проявляется в виде возникновения и развития различных заболеваний или иных вредных последствий, опасных для жизни или здоровья человека. Проанализирован весь перечень видов веществ, которые выступают в качестве предметов преступлений, описанных в статьях особенной части уголовного кодекса. На примере психоактивных веществ главы 25 УК прослежены история развития уголовного законодательства в сфере безопасности здоровья населения 6 международно-правовом и сравнительно-правовом контексте, и те противоречия уголовно-правового регулирования охраны здоровья населения, которые неизбежно возникали и продолжают проявлять себя вследствие отказа от имплементации общепризнанных понятий международного права. На основе ретроспективного анализа понятийных особенностей видов психоактивных веществ высказано мнение о необходимости создания теории уголовно-правовой классификации опасных для здоровья населения веществ, где в качестве одного из критериев отнесения веществ к указанной группе должен выступать признак психоактивности.
\end{abstract}

Review: The article is devoted to the study of the criminal law guarantees of substance turnover within the framework of international law (conventional) obligations of a state and law-making traditions in the sphere of health safety of the population. The substance turnover is recognized as an element to a factor complex, which expresses itself by formation and development of illnesses and other harmful consequences, which are dangerous for life or health of persons. The author analyses the entire list of substances, which may be objects of crimes, as provided for in the Special Part of the Criminal Code of the Russian Federation. Taking psychoactive substance under Chapter 25 of the Criminal Code of the Russian Federation as an example, the author follows the history of development of criminal legislation in the sphere of public health safety in the international legal and comparative legal contexts, and shows the contradictions within the spheres of criminal legal regulation of the public health protection, which inevitable appeared and continued to express themselves when the generally recognized terms of international law were not implemented. Based upon a retrospective analysis of the definition-related specific features of psychoactive drugs, the author expresses an opinion on the need to create a theory of criminal law classification of substance harmful to the population, where one of the criteria for this group should be psychoactive nature of a substance.

Ключевые слова: прекурсоры, одурманивающие вещества, психоактивные вещества, психотропные вещества, аналоги наркотических средств, наркотические средства, незаконный оборот, здоровье населения, уголовная политика, ПККН

Keywords: precursor, intoxicating substances, psychoactive substances, psychedelic substances, analogues to narcotic substances, narcotic substances, illegal turnover, public health, criminal policy 
DOI: $10.7256 / 1811-9018.2013 .10 .2482$

При цитировании этой статьи сноска на dоі обязательна

\section{Право и политика $10(166) \cdot 2013$}

...заканчивая экскурс в английское право, нам хотелось бы акцентировать идею вненационального права, основанного на разуме, которая характеризует общее право. Эта идея противоположна советской концепции права. Она - основа, на которой достигается единство правовых систем западного мира, их независимости от произвольных национальных политик.

Рене Давид. Основные правовые системы современности.

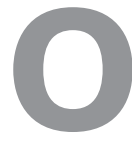

беспечение здоровья населения в общем виде представляет государственную деятельность, направленную на поддержание нормального биосоциального развития человека. Прежде всего, посредством осуществления разноплановых мероприятий по недопущению или ограничению воздействия внешних факторов (биологических, физических, химических, социальных и других), способных создавать угрозу жизни или здоровью человека либо его будущих поколений ${ }^{1}$

Среди множества небезопасных для человека факторов, действие которых проявляется в виде возникновения и развития различных заболеваний или иных вредных последствий, особое место отводится тем, которые связаны с поступлением (преднамеренным или неосторожным) веществ вовнутрь организма. И здесь не имеют значение способы и пути поступления веществ - непосредственно или опосредованно (вместе с вдыхаемым воздухом, потребляемой пищей и водой, через кожные покровы и т.п.), главное, что в последующем это приводит к опасным для человека последствиям. Поэтому оборот веществ, могущих представлять угрозу безопасности жизни и здоровью человека, подлежит строгой технико-правовой регламентации и контролю со стороны государственных органов. Соответственно, виновные лица, допустившие нарушение нормативно установленных правил оборота веществ с опасными свойствами либо совершившие в отношении них незаконные действия, могут быть привлечены к различным мерам юридической ответственности, включая меры уголовно-правового характера. В этой связи определение веществ, оборот которых нуждается в уголовно-правовой охране, является первостепенным.

Принимая во внимание абсолютное число находящихся в обращении конкретных веществ, в диспозициях статей уголовного кодекса указаны их виды, названия которых производны от тех свойств, которые в качестве существенного признака положены в основание их группировки. Перечни самих веществ конкретизируются различными нормативными актами, в основном отраслевыми, в зависимости от сферы

${ }^{1}$ Ст. 1 Федерального закона от 30.03.1999 г. «О санитарно-эпидемиологическом благополучии населения»//РГ. 6.04.1999. № 64-65. использования и назначения веществ, или устанавливаются исходя из разъяснений высших судебных инстанций.

В Особенной части уголовного кодекса выделены следующие виды веществ:

В Особенной части уголовного кодекса названы следующие виды веществ:

- одурманивающие (ст. 151 УК);

- отравляющие (ст. 205, 226.1 УК);

- токсичные ${ }^{2}$ (ст. 205 УК);

- наркотические средства (ст. 228, 228.1, 228.2, 229, 229.1, 230, 232 УК);

- психотропные (ст. 228, 228.1, 228.2, 229, 229.1, 230, 232 УК);

- аналоги наркотических средств или психотропных веществ (ст. 228, 228.1, 229.1, 230, 232 УК) $)^{3}$;

- прекурсоры ${ }^{4}$ (228.2, 228.3. 228.4, 229.1 УК);

- сильнодействующие (ст. 226.1, 234 УК);

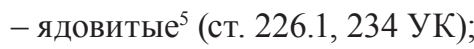

- загрязняющие ${ }^{6}$ (ст. 251 УК);

- химические (ст. 247, 256 УК);

- ядохимикаты ${ }^{7}$ и иные опасные химические или биологические вещества (ст. 254 УК);

\footnotetext{
2 Федеральный закон от 21 июля 1997 г. № 116-Ф3 «О промышленной безопасности опасных производственных объектов» // Собрание законодательства РФ. 28.07.1997. № 30. Ст. 3588.

${ }^{3}$ Федеральный закон от 8 января 1998 г. № 3-Ф3 «О наркотических средствах и психотропных веществах» // Собрание законодательства РФ. 12.01.1998. № 2. Ст. 219.

${ }^{4}$ Постановление Правительства РФ от 30.06.1998. № 681 «Об утверждении перечня наркотических средствах, психотропных веществ и их прекурсоров, подлежащих контролю в Российской Федерации» // Собрание законодательства РФ. № 27. 06.07.1998. Ст. 3198.

${ }^{5}$ Постановление Правительства РФ от 29.12.2007 № 964 «Об утверждении Списков сильнодействующих и ядовитых веществ для целей статьи 234 и других статей уголовного кодекса Российской Федерации, а также крупного размера сильнодействующих и ядовитых веществ для целей статьи 234 уголовного кодекса Российской Федерации // Собрание законодательства РФ. 14.01.2008. № 2. Ст. 89.

${ }^{6}$ Ст.1 Федерального закона от 10.01.2002 г. «Об охране окружающей среды»//РГ. 12.01.2002. № 6.

${ }^{7}$ Постановление Правительства РФ от 09.03.2010 № 132 «Об обязательных требованиях в отношении отдельных видов продукции и связанных с требованиями к ней процессов проектирования
} 
DOI: $10.7256 / 1811-9018.2013 .10 .2482$

При цитировании этой статьи сноска на dоі обязательна

Закон и правопорядок

- иные вещества, представляющие повышенную

опасность для окружающих (ст. 349 УК);

- экологически опасные (ст. 247 УК);

- взрывчатые ${ }^{8}$ (ст. 212, 218, 222, 223, 225, 226, 226.1, 256, 258, 349 УК);

- легковоспламеняющиеся (ст. 218 УК);

- радиоактивные ${ }^{9}$ (ст. 205, 220, 221, 226.1, 247 УК);

- бактериологические (ст. 247 УК);

- вещества, вредные ${ }^{10}$ для здоровья человека и водных биологических ресурсов (ст. 252 УК).

Анализ указанных видов веществ с точки зрения законодательной оценки степени общественной опасности преступлений, предметом которых они выступают, свидетельствует, что наиболее тяжкие уголовно-правовые последствия предусмотрены для посягательств на здоровье населения (гл.25 УК). Преступления, к предмету которых отнесены другие названные виды веществ, являются менее общественно опасными, и способны причинить вред здоровью личности или неопределенному кругу лиц лишь дополнительно или факультативно. Использование веществ при совершении посягательств на общественную безопасность и на отношения в сфере экономики следует рассматривать как отягчающее или особо отягчающее обстоятельства (ст. 205 УК).

Как было выше отмечено, названия видов веществ, предметов соответствующих преступлений, в основном определяются свойствами самих веществ, которые, в ряде случаев, не будучи формально определены, могут одновременно относиться к различным видам. Не касаясь вопроса рациональности выбора названий веществ, притом, что некоторые имеют исключительно уголовно-правовое значение, обратим внимание на то обстоятельство, что сама по себе их видовая множественность отражает достигнутый уровень технологического развития общества и его возможностей по синтезу веществ с требуемыми свойствами. Поэтому любая деятельность по созданию новых веществ или революционное изменение их физи-

(включая изыскания), производства, строительства, монтажа, наладки, эксплуатации, хранения, перевозки, реализации и утилизации, содержащихся в технических регламентах Республики Казахстан, являющейся государством - участником таможенного союза»//Собрание законодательства РФ. 15.03.2010. № 11. Ст.1221.

${ }^{8}$ Постановление Пленума Верховного Суда РФ от 12.03.2002 г. № 5 «О судебной практике по делам о хищении, вымогательстве и незаконном обороте оружия, боеприпасов, взрывчатых веществ и взрывных устройств»//РГ. 19.03.2002. № 48.

${ }^{9}$ Федеральный закон от 21.11.1995 №170-Ф3 «Об использовании атомной энергии»//РГ. № 230. 28.11.1995.

${ }^{10}$ Федеральный закон от 17.12.1998 №191-Ф3 «Об исключительной экономической зоне Российской Федерации» //РГ. № 244. 24.12.1998. ко-химических свойств направлены на последующее их использование в различных сферах общественной жизни (производственной, информационной и т.д.), способствуя, тем самым, утверждению новых форм социальной организации и правоотношений. Следовательно, необходимо научно обоснованное уголовно-правовое прогнозирование возникновения возможных угроз развивающимся общественным отношениям вследствие расширения оборота веществ с опасными свойствами и принятия адекватных мер их уголовно-правовой охраны.

Поскольку из всех веществ гл. 25 УК именно незаконный оборот психоактивных веществ (наркотические средства, психотропные вещества, их аналоги) представляет наибольшую угрозу безопасности здоровья населения и влечет наступление особо тяжких социальных последствий, ретроспективное исследование уголовноправового регулирования веществ с опасными свойствами целесообразно проиллюстрировать на их примере.

В первом УК 1922 г. имелись лишь два вида веществ - сильнодействующие и ядовитые, которые являлись предметом преступления ст.215 УК главы VIII «Нарушение правил, охраняющих народное здравие, общественную безопасность и публичный порядок». ${ }^{11}$ Подобная немногочисленность видов веществ была связана как с общим уровнем промышленного и иного производства, так и потребностью в дополнительной охране тех сфер, в которых непосредственно использовались вещества с наиболее очевидными по своей опасности свойствами - аптеки различных форм собственности, предприятия химической и других отраслей промышленности, кооперативы, артели и т.д.

В связи с распространением заболеваний, обусловленных потреблением некоторых природных и химических веществ, вызывающих состояние опьянения, 22.12.1924 г. УК дополнили ст.140-д Главы IV «Преступления хозяйственные» ${ }^{12}$, которой были криминализированы незаконные действия с веществами, обозначенными как одурманивающие, такими как кокаин, опий, морфий, эфир и им подобными. По сути, с введением данной нормы, содержащей примерный перечень и названия наиболее опасных для здоровья человека веществ, и определяется начало уголовно-правовой борьбы с их незаконным потреблением.

В последующем УК 1926 г. ${ }^{13}$ перечень видов веществ - предметов преступлений против «народного здравия» и, в новой редакции, «порядка управления», никаких из-

\footnotetext{
${ }^{11}$ Собрание узаконений и распоряжений РКПРСФСР. 1922. №15. Ст. 153.

${ }^{12}$ Собрание узаконений и распоряжений РКП РСФСР. 1925. №5. Ст. 33.

${ }^{13}$ СУ РСФСР. 1926. №80. Ст. 600.
} 
DOI: $10.7256 / 1811-9018.2013 .10 .2482$

При цитировании этой статьи сноска на dоі обязательна

\section{Право и политика $10(166) \cdot 2013$}

менений не претерпел. Подобного рода консервация норм уголовного законодательства, как представляется, была обусловлена постепенным превращением государства в закрытое, с жесткой функциональной организацией общество, в котором нерегламентированный оборот опасных для здоровья населения веществ не мог получить достаточное развитие, чтобы представлять социальную проблему. В условиях ликвидации социальных основ свободного рынка и тотального контроля личной и общественной жизни, нелегальный оборот одурманивающих веществ был примитивен и ограничивался преимущественно территориями естественного произрастания содержащих их растений.

Иначе обстояла ситуация в обществах, организованных на принципах свободной внутренней и международной торговли и государственной поддержки частных инициатив, где проблема незаконного оборота природных и искусственно создаваемых веществ с опасными свойствами, особенно по мере развития естественных и прикладных наук, со временем приобрела социально опасные формы. Негативная динамика распространения заболеваемости, вызванной злоупотреблением указанных веществ, потребовала от правительств многих государств объединить усилия в разработке универсальных правовых механизмов противодействия подобного рода угрозам. В результате пришлось пересмотреть представления о правовой природе и видовых особенностях веществ, факторах, детерминирующих проявление их общественно-опасных свойств, характере заболеваний, вызываемых их злоупотреблением, и многих других аспектах незаконного оборота веществ с опасными свойствами, заложив основы исследований новой социальной реальности на высоком междисциплинарном уровне.

Одним из важнейших итогов многолетних усилий на пути решения проблем глобальной безопасности явилось учреждениенового межгосударственного органа-Организации Объединенных Наций. В рамках данного международного институтав 1961 г. был принят первый нормативный правовой акт-Конвенция ООН «О наркотических средствах» (ратифицирована Указом Президиума ВС СССР от 14.12.1963), включавшая в себя унифицированные обязательстваподписавших еегосударств попротиводействиюраспространению опасных для здоровья населения веществ по прилагаемому перечню.

В уголовном кодексе РСФСР 1960 г...$^{14}$ были учтены требования конвенционных норм о контроле над оборотом наркотических средств, которыми был дополнен традиционный перечень предметов преступлений против

${ }^{14}$ Ведомости Верховного Совета РСФСР. 1960. № 40. Ст.591. «здоровья населения» в рамках единой для всех диспозиции ст.224 УК. Но, несмотря на международно-правовые стандарты, обеспечивающие понятийное единство национальных законодательств, в УК РСФСР 1960 г. вместо понятия «наркотические средства» был использован его аналог «наркотические вещества». Причем данное понятие было перенесено в Уголовный кодекс 1996 г. (ст. 231 УК), и просуществовало в качестве самостоятельной языковой единицы вплоть до 18.11.2010 г. ${ }^{15}$ То есть, понадобилось 49 лет, чтобы лексика Российского уголовного законодательства была приведена в соответствие с общепринятой терминологией международного права. Необходимо добавить, что в ст. 226 УК «Содержание притонов и сводничество» предметом преступления являлись не наркотические вещества, а «наркотики», понятием которых, надо полагать, охватывались также и иные наркотически действующие вещества.

Безусловно, достигнутый уровень развития химической науки и технологий синтеза веществ обусловили потребность в изменении средств уголовно-правовой охраны здоровья населения, хотя признать их криминологически необходимыми было сложно. Ведь проблема контроля над оборотом опасной для здоровья населения продукции с высокой добавочной стоимостью представляла актуальность, прежде всего, для западных стран, поскольку именно в этих странах произошла научно-техническая революция, которая не только качественно изменила весь общественный уклад, но и обусловила возникновение новых разновидностей технологических угроз. Более того, существующие условия свободной внутренней и международной торговли во многом способствовали распространению химической и фармацевтической продукции двойного назначения, особенно со стороны стран с недостаточно развитой системой их нормативного контроля.

Имплементация норм Конвенции ООН, безусловно, повысила, по крайней мере, терминологический уровень уголовного законодательства в сфере охраны здоровья населения, придав ему большую научность. Однако понятие нового вида веществ лишь дополнило действующий перечень предметов преступлений, не послужив толчком для развития их правовой категории. Отнесение вещества к наркотическому или сильнодействующему определялось лишь его принадлежностью к одному из утвержденных

\footnotetext{
${ }^{15}$ Федеральный закон от 19.05.2010 N 87-Ф3 «О внесении изменений в отдельные законодательные акты Российской Федерации по вопросу культивирования растений, содержащих наркотические средства или психотропные вещества либо их прекурсоры» // Собрание законодательства РФ. 24.05.2010. N 21. Ст. 2525.
} 
DOI: $10.7256 / 1811-9018.2013 .10 .2482$

При цитировании этой статьи сноска на dоі обязательна

Закон и правопорядок

Минздравом списков. Одурманивающими стали считаться любые иные формально неопределенные вещества, обладавшие соответствующими их наименованию свойствами. Как представляется, изменения в средствах уголовно-правовой охраны здоровья населения носили скорее технико-юридический, нежели содержательный характер, своего рода, законодательное выражение участия государства в важнейших международно-правовых институтах, а не свидетельство развития теории незаконного оборота веществ с опасными свойствами.

Успехи мировой науки в создании (конструировании) препаратов для лечения нарушений мозговой деятельности, способные вызывать те же вредные последствия, что и наркотические средства, обусловили принятие в 1971 г. Конвенции ООН «О психотропных веществах» (ратифицированной Указом Президиума Верховного Совета СССР от 23.10.1978 года), нормативно закрепившей юридическое понятие нового вида веществ и их перечень. Между тем, ратификация Конвенции ООН, создававшая правовые основы регулирования общественных отношений, возникших по поводу включения в торговый оборот лекарственных веществ с опасными свойствами, на состояние науки уголовного права и законодательства никакого влияния не оказала, поскольку международно-правовое понятие, которым определялся новый вид опасных для здоровья населения веществ, отечественным уголовным законодательством воспринят не был. Понятие данных веществ сохранило исключительно медицинское значение, в то время как сами вещества конвенционного перечня были распределены по спискам наркотических средств или сильнодействующих веществ.

Не изменился единожды закрепленный подход к определению статуса психотропных веществ и после введения их понятия во вновь принятый Уголовный кодекс РФ 1996 года. Прежде всего, их перечень был утвержден постановлением Правительства спустя 1,5 года-30 июня 1998 года, и включал лишь часть психотропных веществ одноименной Конвенции ООН, а другие психотропные вещества продолжали значиться в списках наркотических средств и сильнодействующих веществ.

Подобная понятийная многозначность опасных для здоровья веществ, правовой статус которых не соответствовал тому, который был определен нормативным правовым актом наивысшей юридической силы, просуществовала 42 года. Лишь с принятием постановления Правительства РФ от 4.02.2013 №78 ${ }^{16}$, которым сильнодействующие вещества

\footnotetext{
${ }^{16} \mathrm{O}$ внесении изменений в некоторые акты Правительства Российской Федерации//Собрание законодательства РФ. 11.02.2013. N 6. Ст. 558.
}

конвенционного перечня были перенесены в список психотропных веществ, приоритет международного права получил законодательное признание, и психотропные вещества обрели свои законные наименование и статус.

Неприятие общепринятых международно-правовых форм выражения проблем безопасности здоровья населения в немалой степени было обусловлено отсутствием криминологических предпосылок для уголовно-правовых новаций, если учесть тот крайне низкий уровень незаконного оборота подобных веществ, характерный для экономики с директивной системой распределения произведенного продукта, к тому же весьма дефицитного. Следует также учитывать тот факт, что вплоть до 1985 г. партийно-государственная доктрина исходила из окончательности решения проблем наркомании и токсикомании ${ }^{17}$, тем самым, исключалась сама необходимость криминологического изучения социальных основ детерминации данных заболеваний.

Однако, смена общественно-государственного устройства, переход к свободной рыночной экономике определили потребность в иных средствах уголовноправовой охраны безопасности здоровья населения, адекватных складывающимся условиям незаконного оборота опасных психоактивных веществ. И если в странах Запада в результате непрерывных исканий утвердились разные правовые модели профилактики и борьбы с немедицинским потреблением всевозможных видов психоактивных веществ на строгой научно-практической основе, не подвергая сомнению демократические свободы, то здесь многое предстояло осуществить впервые.

Во вновь принятом уголовном кодексе РФ 1996 г. к формулированию норм о безопасности здоровья населения подошли несколько хаотично, руководствуясь в нормотворческой деятельности не системой правовых знаний об опасных психоактивных веществах, уголовно-правовая категория которых до сих пор не выработана, а международными обязательствами государства и сомнительными субъективными предпочтениями.

В итоге существующий видовой перечень был дополнен следующими видами:

-психотропные вещества (ст. 228, 229; 230, 232, 233 УК).

- вещества, используемые для изготовления наркотических средств или психотропных веществ, находящихся под специальным контролем (ч. 5 ст. 228 УК). Кстати заметить, в Федеральном законе от 08.01.1998 № 3-Ф3 «О наркотических средствах и психотропных веществах» данные вещества в иной редакции были

\footnotetext{
${ }^{17}$ Ткачевский Ю.М. Правовые аспекты борьбы с наркоманией и
} алкоголизмом.- М.:Профиздат,1990. С.3. 
DOI: $10.7256 / 1811-9018.2013 .10 .2482$

При цитировании этой статьи сноска на dоі обязательна

\section{Право и политика $10(166) \cdot 2013$}

определены как прекурсоры. Однако понятие прекурсоров в качестве самостоятельного предмета преступления было включено в уголовный кодекс Федеральным законом от 19.05.2010 № 87-Ф3 ${ }^{18}$ лишь спустя 14 лет.

Также, несмотря на то, что Федеральным законом «О наркотических средствах и психотропных веществах» было введено понятие аналогов наркотических средств или психотропных веществ, значение предмета преступления (ст. 228, 228.1 УК) они приобрели лишь спустя 5 лет на основании Федерального закона от 8 декабря 2003 года № $162-Ф 3^{19}$.

Однако как показывает анализ развития уголовного законодательства в сфере незаконного оборота опасных для здоровья населения веществ, в силу общественнополитических, идеологических и других причин труды ученых не смогли определить становление данной отрасли права в контексте ее международно-правового развития. Возможно и по причине того, что в условиях тотальной государственной регламентации всех сторон общественной жизни и полного запрета частнопредпринимательской деятельности, нецелевое использование достижений естественных наук, в данном случае, в области фармакологии лекарственных средств, химического синтеза и т.д., было незначительным. Поэтому незаконный оборот высокотехнологичной фармацевтической или химической продукции, не имея заметных общественно опасных проявлений, не мог выступать криминологическим фактором совершенствования норм о безопасности здоровья населения. Соответственно, не могла возникнуть необходимость в разработке теоретических основ уголовно-правового обеспечения рассматриваемых, и представлявшихся незыблемыми, общественных отношений даже с появлением технологических возможностей по созданию новых веществ с требуемыми свойствами.

Включение в уголовное законодательство понятия наркотических веществ (средств), проблема незаконного оборота которых имела широкое международное обсуждение, при отсутствии внутренних научных предпосылок, не послужило толчком для развития их правового феномена, ограничившись рамками предмета преступления в комментариях к статьям уголовного

\footnotetext{
${ }^{18}$ О внесении изменений в отдельные законодательные акты Российской Федерации по вопросу культивирования растений, содержащих наркотические средства или психотропные вещества либо их прекурсоры// Российская газета. № 109. 21.05.2010.

${ }^{19} \mathrm{O}$ внесении изменений и дополнений в Уголовный кодекс Российской Федерации // Российская газета. № 252. 16.12.2003.
}

кодекса. Поэтому вопросы сущности и содержательных различий наркотических средств и, впоследствии, психотропных веществ, а также сильнодействующих и одурманивающих веществ, которые в уголовном законе представлены изначально, по-прежнему остаются вне обсуждений. Сохраняют неясность признаки, положенные в основание группировки видов веществ, в силу которых отнесение их к перечню других веществ нецелесообразно или невозможно. Соответственно непонятны критерии включения вновь созданного вещества, обладающего психоактивными свойствами, в конкретный видовой перечень со всеми вытекающими из данного решения уголовно-правовыми последствиями. Не исключено, что сформированные списки предполагалось рассматривать как окончательные, а к синтезу новых психоактивных веществ подходить с точки зрения аналогов наркотиков.

В то же время, исходя из содержания опубликованных работ, невозможно проследить развитие научной мысли, предваряющей введение в уголовный закон новеллы об аналогах наркотиков, а также критериях, позволяющих правоохранительным органам идентифицировать конкретное вещество в качестве последнего. И подобная нормативно-правовая безысходность продолжает иметь место более 15 лет, несмотря на множество работ, традиционно касающихся наркотических средств, а точнее, совершаемых в отношении них действий, не раскрывающих содержания веществ и их места в системе видов веществ, опасных для здоровья населения.

Неразработанность наукой уголовного права исходных принципов группировки опасных для здоровья населения, по сути, их полное отсутствие, явилось одной из причин издания Постоянным комитетом по контролю наркотиков (далее - ПККН) в 1996 г. приказа об утверждении списка одурманивающих веществ ${ }^{20}$, которым закреплялся их формально-правовой статус. Навязанное понимание категории данных веществ нашло отражение в учебниках по уголовному и административному праву, выступив педагогической основой формирования неверных представлений об их уголовно-правовом значении. Притом, что подобной оценки одурманивающих веществ, к которым относятся вещества из конечного списка, практика правоприменения не знает.

Таким образом, если по нормам УК 1922 и 1926 г.г. к одурманивающим относились любые вещества, схожие

\footnotetext{
${ }^{20}$ Список одурманивающих веществ (по состоянию на 1.11.2005 г.) (утв. на заседании ПККН 9.10. 1996 г.) // Новые лекарственные препараты. 2005. № 11.
} 
DOI: $10.7256 / 1811-9018.2013 .10 .2482$

При цитировании этой статьи сноска на доі обязательна

Закон и правопорядок

по воздействию с кокаином, морфием, опием, эфиром, и способные в соответствии со значением термина, дурманить сознание, то сейчас это самостоятельный вид веществ, обладающих только им присущими свойствами. Проблема искусственной трансформации понятия в результате псевдонормотворческой деятельности ПККН, способной повлечь крайне сомнительные изменения в регулировании общественных отношений, здесь видится не главной. Существенно то, что данное решение авторами учебно-практических пособий по уголовному и административному праву ${ }^{21}$ было воспринято как бесспорное, создав своеобразный мультикативный эффект распространения ошибочных знаний о предмете преступления.

В настоящее время ПККН лишен функций, реализацией которых определялась вся уголовно-правовая политика в сфере безопасности здоровья населения, - в частности, по формированию списков подлежащих контролю веществ, представляющих опасность для здоровья населения, и установлению величины их крупных размеров. Вместе с тем, правильное решение о передаче подобных полномочий в компетенцию Правительства РФ в ряде случаев осложнило практику правоприменения. Ведь крупные размеры приведены для наиболее часто изымаемых психоактивных веществ, доля которых в общей номенклатуре веществ сравнительно невелика. И если ранее была наработана практика получения рекомендаций по размеру изымаемого вещества путем направления соответствующим субъектом правоприменения запроса в ПККН, то сейчас подобный механизм получения заключения, которым определяется преступность деяния, отсутствует.

ПККН, при всех обсуждаемых моментах, являлся наиболее открытым научно-консультативным органом, издававшим множество работ теоретико-правового характера, отличавшихся конкретикой и разумным изложением. Даже анализ выписок из протоколов заседаний ПККН, которые публиковались в печатных изданиях, позволял проследить логику принимаемых им решений. С уходом из правового поля данного коллектива экспертов, творческий потенциал которого определялся личностью профессора медицины, академика Бабаяна

${ }^{21}$ См.: Косевич И.А. Уголовное право России. Части Общая и Особенная: учебник/под ред. А.В. Бриллиантова. - М.: Проспект, 2009. С.517; Комментарий к Кодексу Российской Федерации об Административных правонарушениях (постатейный) с постатейными материалами. 9-издание переработанное и дополненное. Автор комментариев и составитель - В.С. Чижевский - М.: Книжный мир, 2008. С.187.
Э.А., уровень научных изысканий, как полагаем, несколько снизился.

В заключение, нельзя не затронуть вопрос, так сказать, уголовно-правового подполья, а именно, о ядовитых веществах - предмете преступлений, предусмотренных ст.234 УК. Несмотря на то, что их понятие содержится в уголовном законодательстве на протяжении всей истории, исследованию оно не подвергалось, в постановлениях Пленума Верховного Суда (1993, 1998, 2006 г.г.) их значение никогда не раскрывалось, и даже признак крупного размера не определен. Поэтому обсуждение проблем незаконного оборота данных опасных для здоровья населения веществ, которые, как следует из их названия, являются чрезвычайно токсичными, хотя некоторые используются для внутривенной инъекции, при существующем уровне научного постижения их понятия весьма сложно.

В целях снижения, по крайней мере, неопределенности поставленных выше вопросов и развития данного направления уголовно-правовой мысли необходимо создание теории уголовно-правовой классификации опасных для здоровья населения веществ, где в качестве одного из критериев отнесения веществ к указанной группе должна выступать их психоактивность. По сути, предлагается разработка вопросов уголовной политики в направлении, достаточно полно исследованном в педагогике, психологии, социологии, медицине, и нашедшем отражение в международно-правовых актах. Представление структуры данных веществ позволит избежать многих ошибок и неточностей в формулировании механизма правового регулирования их оборота. В частности, это позволит лучше понимать их место в системе веществ опасных для здоровья населения, и тот объем социального вреда, который обусловливает их незаконный оборот в сравнении, например, с потреблением спиртных напитков, пива, табака.

\section{Библиография:}

1. Федеральный закон от 30.03.1999 г. «О санитарноэпидемиологическом благополучии населения»// РГ. 6.04.1999. № 64-65.

2. Федеральный закон от 10.01.2002 г. «Об охране окружающей среды»//РГ. 12.01.2002. № 6.

3. Федеральный закон от 08.01.1998 № 3-Ф3 «О наркотических средствах и психотропных веществах» // Собрание законодательства РФ. 12.01.1998. № 2. Ст. 219. 
DOI: $10.7256 / 1811-9018.2013 .10 .2482$

При цитировании этой статьи сноска на доі обязательна

\section{Право и политика $10(166) \cdot 2013$}

4. Федеральный закон от 21 июля 1997 г. № 116-Ф3 «О промышленной безопасности опасных производственных объектов».//Собрание законодательства РФ. 28.07.1997. № 30. Ст. 3588.

5. Федеральный закон от 19.05.2010 N 87-ФЗ «О внесении изменений в отдельные законодательные акты Российской Федерации по вопросу культивирования растений, содержащих наркотические средства или психотропные вещества либо их прекурсоры» // Собрание законодательства РФ. 24.05.2010. № 21. Ст. 2525.

6. Федеральный закон от 8 декабря 2003 года N 162-Ф3 «О внесении изменений и дополнений в Уголовный кодекс Российской Федерации» // Российская газета. № 252. 16.12.2003.

7. Федеральный закон от 21.11.1995 №170-Ф3 «Об использовании атомной энергии»//РГ. № 230. 28.11.1995.

8. Федеральный закон от 17.12.1998 №191-Ф3 «Об исключительной экономической зоне Российской Федерации» //РГ. № 244. 24.12.1998.

9. Постановление Правительства РФ от 30.06.1998. № 681 «Об утверждении перечня наркотических средствах, психотропных веществ и их прекурсоров, подлежащих контролю в Российской Федерации».//Собрание законодательства РФ. № 27. 06.07.1998. Ст. 3198.

10. Постановление Правительства РФ от 29.12.2007 № 964 «Об утверждении Списков сильнодействующих и ядовитых веществ для целей статьи 234 и других статей уголовного кодекса Российской Федерации, а также крупного размера сильнодействующих и ядовитых веществ для целей статьи 234 уголовного кодекса Российской Федерации. // Собрание законодательства РФ. 14.01.2008. № 2. Ст. 89.

11. Постановление Правительства РФ от 4.02.2013 №78 «О внесении изменений в некоторые акты Правительства Российской Федерации»//Собрание законодательства РФ. 11.02.2013. N 6. Ст. 558.

12. Постановление Правительства РФ от 09.03.2010 № 132 «Об обязательных требованиях в отношении отдельных видов продукции и связанных с требованиями к ней процессов проектирования (включая изыскания), производства, строитель- ства, монтажа, наладки, эксплуатации, хранения, перевозки, реализации и утилизации, содержащихся в технических регламентах Республики Казахстан, являющейся государством-участником таможенного союза»//Собрание законодательства РФ. 15.03.2010. № 11. Ст.1221.

13. Постановление Пленума Верховного Суда РФ от 12.03.2002 г. № 5 «О судебной практике по делам о хищении, вымогательстве и незаконном обороте оружия, боеприпасов, взрывчатых веществ и взрывных устройств»//РГ. 19.03.2002. № 48.

14. Постановление ВЦИК от 01.06.1922 «О введении в действие Уголовного Кодекса Р.С.Ф.С.Р.» (вместе с «Уголовным Кодексом Р.С.Ф.С.Р.»)//Собрание узаконений и распоряжений РКП РСФСР. 1922. №15. Ст. 153.

15. Собрание узаконений и распоряжений РКП РСФСР. 1925. №5. Ст. 33.

16. Кодекс РСФСР от 22.11.1926//СУ РСФСР. 1926. №80. Ст. 600 .

17. Кодекс РСФСР от 27.10.1960 // Ведомости Верховного Совета РСФСР. 1960. № 40. Ст.591.

18. Список одурманивающих веществ (по состоянию на 1.11.2005 г.) (утв. на заседании ПККН 9.10. 1996 г.) // Новые лекарственные препараты. 2005. № 11.

19. Косевич И.А. Уголовное право России. Части Общая и Особенная: учебник/под ред. А.В. Бриллиантова.-М.: Проспект, 2009. С.517.

20. Комментарий к Кодексу Российской Федерации об Административных правонарушениях (постатейный) с постатейными материалами. 9-издание переработанное и дополненное. Автор комментариев и составитель - В.С. Чижевский - М.: Книжный мир, 2008. С.187.

21. Ткачевский Ю.М. Правовые аспекты борьбы с наркоманией и алкоголизмом. - М.: Профиздат, 1990. C.3.

\section{References (transliteration):}

1. Kosevich I.A. Ugolovnoe pravo Rossii. Chasti Obshchaya i Osobennaya: uchebnik/pod red. A.V. Brilliantova.-M.: Prospekt, 2009. S.517.

2. Tkachevskii Yu.M. Pravovye aspekty bor'by s narkomaniei i alkogolizmom.- M.:Profizdat,1990. S.3. 